\section{Acute Appendicitis: Hispanics and the Hamburger Sign}

\author{
Garcia Gubern C ${ }^{1}$, Colon Rolón L1, Ruiz Mercado I , Oliveras \\ Garcia $\mathrm{C}^{1}$, Caban Acosta $\mathrm{D}^{1}$, Muñoz Pagán $\mathrm{J}^{1}$, Iriarte $\mathrm{I}^{3}$, Bolaños \\ Ávila $\mathrm{G}^{2}$, Peguero Rivera $\mathrm{J}^{2}$, Sánchez Gaetan $\mathrm{F}^{2}$, Oneill Castro $\mathrm{J}^{2}$, \\ Cordero Colón Paola N ${ }^{1}$, Garcia-Colon Carlos A $^{1}$ and Romero- \\ Vazquez Ana $\mathbf{M}^{4 *}$
}

${ }^{1} \mathrm{MD}$, Department of Emergency Medicine Hospital San Lucas, Ponce, Puerto Rico ${ }^{2}$ Department of Surgery Hospital San Lucas, Ponce, Puerto Rico

${ }^{3}$ Ponce Health and Sciences University, Ponce, School of Public Health, Puerto Rico ${ }^{4}$ Ponce Health and Sciences University, Ponce, School of Medicine, Puerto Rico

\section{Abstract}

Objective: To describe the presenting clinical findings of patients with acute appendicitis and compare them with those described in the medical literature. To corroborate a common medical myth among Hispanic physicians regarding the presentation of acute appendicitis.

Methods: This was a retrospective multicenter chart review of patients diagnosed postoperatively with appendicitis after presenting to five different Emergency Departments in Southern Puerto Rico (PR).

Results: A total of 1,540 patients with pathologically confirmed cases of appendicitis were enrolled in our study. Of the study population, $45 \%$ were female, and $55 \%$ were male, and $43 \%$ were over 21 years old. Reported symptoms in our study showed that $98 \%$ of the patients had abdominal pain, $47 \%$ had nausea, and only $17.6 \%$ presented with anorexia.

Conclusion: It was our main objective to compare the presenting signs and symptoms of patients with acute appendicitis in our Hispanic population in southern PR with those found in primary medical textbooks and literature. We gathered information regarding signs and symptoms, as well as laboratory and radiographic data of patients with positive pathologic exams for appendicitis. Of the 1,540 patients with confirmed appendicitis, only $17.6 \%$ presented with anorexia. Our findings demonstrate that the rate of anorexia in the studied population is significantly lower when compared to current literature. The absence of anorexia, once considered a hallmark of appendicitis, must not lead the physician to rule out this diagnosis in the Hispanic population.

\section{More Information}

*Address for Correspondence: RomeroVazquez Ana M, MS, Ponce Health and Sciences University, Ponce, Puerto Rico- School of Medicine, Puerto Rico, Tel: (787)363-6739; Email: romero.vazquez.ana@gmail.com; aromero16@stu.psm.edu

Submitted: 12 November 2019

Approved: 19 November 2019

Published: 20 November 2019

How to cite this article: Garcia Gubern C, Colon Rolón L, Ruiz Mercado I, Oliveras Garcia C, Caban Acosta D, et al. Acute Appendicitis: Hispanics and the Hamburger Sign. Arch Surg Clin Res. 2019; 3: 078-081.

DOI: dx.doi.org/10.29328/journal.ascr.1001041

ORCiD: orcid.org/0000-0001-7214-0748

Copyright: @ 2019 Garcia Gubern C, et al. This is an open access article distributed under the Creative Commons Attribution License, which permits unrestricted use, distribution, and reproduction in any medium, provided the original work is properly cited.

(D) Check for updates

\section{Introduction}

Abdominal pain is a common complaint in the emergency department (ED); it is one of the most complex presenting symptoms with an extensive array of possible differential diagnoses. At any given ED, life-threatening conditions must be excluded as possible diagnoses to prevent deadly complications. A common life-threatening abdominal condition is acute appendicitis [1-19].

The appendix was once considered a vestigial organ but is now well recognized as being an immunologic organ that actively participates in the secretion of immunoglobulins. One in one thousand $(1 / 1,000)$ persons in the general population will be diagnosed with acute appendicitis [1,4,5,15].
There is no gender or age predilection for this condition. Appendectomy for appendicitis is the most commonly performed emergency operation worldwide $[3,7,15,17]$. Appendicitis occurs most commonly in the young, with $40 \%$ of the cases occurring in patients between the ages of 10 and 29 years old $[15,17]$.

The presentation of acute appendicitis usually begins with diffuse, epigastric, or periumbilical pain of visceral origin that progresses to a parietal-derived pain that is localized to a specific region-usually in the right lower quadrant (RLQ). Commonly associated symptoms have been described, such as anorexia, nausea, vomiting, and fever $[1,3,5,7,12,15,17]$.

The differential diagnosis of acute appendicitis depends 
on four major characteristics: the anatomic location of the inflamed appendix, the stage of the process (i.e., simple or ruptured), the patient's age, and the patient's sex $[15,17]$ (Table 1).

This retrospective cohort study included patients that were diagnosed post-operatively with acute appendicitis. The initial presentation, physical examination, and laboratory values were reviewed in order to improve the early identification of patients with acute appendicitis. The study was organized by the Departments of Emergency Medicine of Hospital Episcopal San Lucas (HESL) and Ponce Health Sciences University-School of Medicine (PHSU-SOM), both of which are located in Ponce, PR. The information was extracted from patient medical records from several hospitals in the southern region of PR, including HESL in Ponce, HESL in Guayama, Saint Luke's Memorial Hospital in Ponce, Hospital San Cristobal in Ponce, and Hospital Metropolitano Dr. Tito Mattei in Yauco (Figure 1).

\section{Methods}

Available medical records of appendectomies performed

Table 1: Differential Diagnosis of Acute Appendicitis.

\begin{tabular}{|c|c|c|}
\hline Gastrointestinal & Gynecologic & Genitourinary \\
\hline $\begin{array}{l}\text { - Abdominal Pain, Cause } \\
\text { - Unknown } \\
\text { - Crolecystitis } \\
\text { - Diverticulitis } \\
\text { - Duodenal Ulcer } \\
\text { - Gastroenteritis } \\
\text { - Intestinal Obstruction } \\
\text { - Intussusception } \\
\text { - Meckel's Diverticulitis } \\
\text { - Mesenteric Lymphadenitis } \\
\text { - Necrotizing Enterocolitis } \\
\text { - Neoplasm (Carcinoid, } \\
\text { - Carcinoma, Lymphoma) } \\
\text { - Pmental Torsion } \\
\text { - Perforatitis } \\
\text { - Volvulus }\end{array}$ & $\begin{array}{l}\text { - Ectopic Pregnancy } \\
\text { - Endometriosis } \\
\text { - Ovarian Torsion } \\
\text { - Pelvic Inflammatory Disease } \\
\text { - Ruptured Ovarian Cyst } \\
\text { - } \text { (Follicular, Corpus Luteum) } \\
\text { - Tubo-Ovarian Abscess }\end{array}$ & $\begin{array}{l}\text { - Kidney Stone } \\
\text { - Prostatitis } \\
\text { - Pyelonephritis } \\
\text { - Testicular } \\
\text { - Torsion } \\
\text { - Urinary Tract } \\
\text { - Infection } \\
\text { - Wilms' Tumor }\end{array}$ \\
\hline Systemic & Pulmonary & Other \\
\hline $\begin{array}{l}\text { - Diabetic Ketoacidosis } \\
\text { - Porphyria } \\
\text { - } \text { Sickle Cell Disease } \\
\text { Purpura }\end{array}$ & $\begin{array}{l}\text { - Pleuritis } \\
\text { - Pneumonia (basilar) } \\
\text { - Pulmonary Infarction }\end{array}$ & 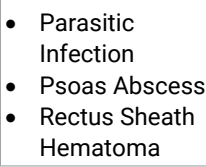 \\
\hline
\end{tabular}

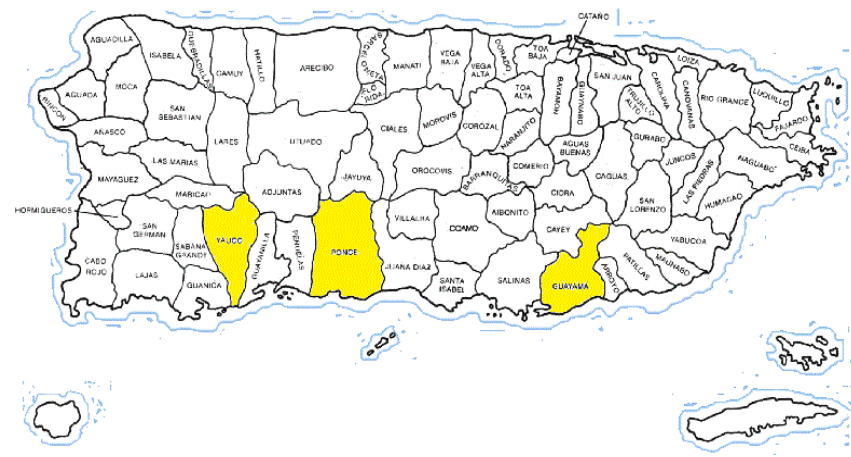

Figure 1: Map of Puerto Rico and Municipalities. at five hospitals in southern PR from January 1, 2008, through December 31, 2014 were reviewed. The hospital medical records of all patients with a post-surgical diagnosis of acute appendicitis were retrieved and studied. Only those cases confirmed as acute appendicitis by pathological examination were included in the study.

The following demographic data was obtained from medical records: age, sex, and ethnicity. From the visit to the ED, the data collected included the chief complaint and symptoms presented in the ED. The symptoms presented that this study emphasized on when extracting data included: abdominal pain, fever (defined as a temperature of $38^{\circ} \mathrm{C}$ or above), anorexia, nausea, vomiting, diarrhea, constipation, and dysuria. Clinical findings of pain and location, as well as the presence or absence of guarding, rebound tenderness, psoas sign, obturator sign, Rovsing's sign, cervical motion tenderness, and rectal tenderness were also documented. Laboratory and imaging studies data as well as pathological examinations were obtained for each patient. Leukocytosis was defined as a white blood cell (WBC) count greater than $11,000 / \mathrm{uL}$, and pyuria was considered present when more than $10 \mathrm{WBC} / \mathrm{hpf}$ were found on urinalysis $[12,13]$. The time intervals from the onset of symptoms to presentation in the $E D$, though varied, were divided in days: less than one day, one day to four days, and more than four days.

This study was approved by the IRB. Patient identifiers were not included in the data gathering process of this retrospective study; thus, patient informed consent forms were not required.

\section{Results}

Acute appendicitis was pathologically confirmed in 1,679 patients. One hundred thirty-nine of those patients were excluded because records were incomplete, or patients were not of Hispanic ethnicity. A total of 1,540 medical charts were reviewed and studied.

Of the 1540 patients with confirmed acute appendicitis, $55 \%$ were male and $45 \%$ were female, yielding a ratio of 1.22 to 1 . Patients were divided into pediatric (younger than 21 years old) and adult ( 21 years or older); $57 \%$ of the population was younger than 21 years old, and $43 \%$ of the population was 21 years or older. The study sample was divided based on two surgical criteria: perforated appendix and non-perforated appendix.

The average time since onset of symptoms to medical evaluation for pediatric patients was 1.7 days, and for adult patients the average was 1.4 days. Regarding perforation vs. non-perforation, the average time since onset of symptoms to medical evaluation was 1.4 days for patients with non-perforated appendicitis and 2.2 days for those with perforated appendicitis. 
Abdominal pain was documented upon triage and/or evaluation at the emergency department in 1,509 (98.0\%) of our patients. Of those 1,509 patients with abdominal pain, $400(26.5 \%)$ reported that the abdominal pain was greater at the RLQ.

Of the associated symptoms recorded, 693 (45.0\%) patients reported fever, 271 (17.6\%) patients reported anorexia, 727 (47.2\%) patients reported nausea, 798 (51.8\%) patients reported vomiting, 299 (19.4\%) patients reported diarrhea, 41 (2.7\%) patients reported constipation, and 201 (13.1\%) patients reported dysuria (Table 2).

From the documented physical exams, 1,347 (87.5\%) patients presented with RLQ tenderness-which was the most common physical exam finding documented in our sample population. Associated findings included guarding in $978(63.5 \%)$ patients, rebound tenderness in 1,156 (75.1\%) patients, psoas sign in 602 (39.1\%) patients, obturator sign in 585 (38.0\%) patients, and Rovsing's sign in 677 (44.0\%) patients (Table 3).

Basic laboratory workups for these patients included a complete blood count and urinalysis. 773 (50.2\%) patients were found with a high leukocyte count (above 11,000/uL) and a marked neutrophilic predominance in the white blood cell count. Urinalysis results were normal in the majority of the cases, and only 264 (17.1\%) patients had pyuria (defined here as having more than $10 \mathrm{WBC} / \mathrm{hpf}$ ).

A total of 1,601 imaging studies were performed in our sample population; these included plain radiographs, abdominal ultrasound studies, and abdominal-pelvic CTScans. Patients in this study had one, two or three imagining studies performed based on their clinical presentation and the ED they visited. For the purpose of reporting data, percentages of imaging findings were based on the study sample size

Table 2: Symptoms.

\begin{tabular}{|c|c|c|c|c|c|c|}
\hline History & Present $\%$ Present & Denied & \% Denied & $\begin{array}{c}\text { Not } \\
\text { Documented }\end{array}$ & $\begin{array}{c}\text { \% Not } \\
\text { Documented }\end{array}$ \\
\hline $\begin{array}{c}\text { Abdominal } \\
\text { pain }\end{array}$ & 1,509 & 98.0 & 31 & 2.0 & 0 & 0 \\
\hline Fever & 693 & 45.0 & 826 & 53.6 & 21 & 1.4 \\
\hline Anorexia & 271 & 17.6 & 1,256 & 81.6 & 13 & 0.8 \\
\hline Nausea & 727 & 47.2 & 793 & 51.5 & 20 & 1.3 \\
\hline Vomiting & 798 & 51.8 & 737 & 47.9 & 5 & 0.3 \\
\hline Diarrhea & 299 & 19.4 & 1,191 & 77.3 & 46 & 2.9 \\
\hline Constipation & 41 & 2.7 & 664 & 43.1 & 835 & 54.2 \\
\hline Dysuria & 201 & 13.1 & 1248 & 81.0 & 91 & 5.9 \\
\hline
\end{tabular}

Table 3: Physical Exam Findings

\begin{tabular}{|c|c|c|c|c|c|c|}
\hline $\begin{array}{c}\text { Physical } \\
\text { Exam }\end{array}$ & Present & $\%$ Present & Absent & $\%$ Absent & $\begin{array}{c}\text { Not } \\
\text { Documented }\end{array}$ & $\begin{array}{c}\% \text { Not } \\
\text { Documented }\end{array}$ \\
\hline Guarding & 978 & 63.5 & 432 & 28.1 & 130 & 8.4 \\
\hline Rebound & 1,156 & 75.1 & 260 & 16.9 & 124 & 8.1 \\
\hline Psoas & 602 & 39.1 & 498 & 32.3 & 440 & 28.6 \\
\hline Obturator & 585 & 38.0 & 410 & 26.6 & 545 & 35.4 \\
\hline Rovsing's & 677 & 44.0 & 348 & 22.6 & 525 & 34.1 \\
\hline RLQ-Pain & 1,347 & 87.5 & 193 & 12.5 & 0 & 0 \\
\hline
\end{tabular}

and not on the amount of imaging studies performed. Plain radiographs of the abdomen were performed in 508 (33.0\%) patients; of these, $11(2.2 \%)$ studies were remarkable for appendiceal fecalith and $10(2.0 \%)$ studies were remarkable for a degree of obstruction that ranged in complication from appendiceal gas to a localized paralytic ileus. Ultrasound imaging was performed on 127 (8.2\%) patients; of these only $19(15.0 \%)$ studies were found with a non-compressible appendix suggestive of appendicitis. A total of 426 (27.7\%) CT Scans were performed and $80 \%$ of these ordered scans were performed with contrast, either oral or intravenous. Of the 426 abdominal scans, 228 (53.5\%) were reported with an abnormal finding (early appendicitis, RLQ fat standing, nonspecific inflammatory changes, abnormal gas pattern, perforated appendix, appendix foreign body, acute appendicitis) and 198 (46.5\%) were reported as negative.

\section{Discussion}

The results of this study show that in our sample population, the associated signs and symptoms of patients with acute appendicitis in comparison with those classically discussed in major reference textbooks differ principally in terms of the frequency of anorexia, nausea, psoas and obturator signs.

The clinical diagnosis of appendicitis is based on a given patient's history and physical examination. The most common symptoms described in the major textbooks are abdominal pain and anorexia. The most common physical findings are RLQ tenderness, guarding, and rebound. The most common signs and symptoms presented in the literature compared to those found by our study are shown in table 4 .

For medical professionals who trained in Puerto Rico, the Caribbean and South America, the concept of the "Hamburger sign" is something that comes to mind when evaluating patients with abdominal pain that is suspicious of acute appendicitis. Most patients in these demographical areas would present with increased appetite, as opposed to patients presenting with anorexia in the rest of the population of the western hemisphere. With our study results, we were able to validate this theory of the "Hamburger sign" given that $17.6 \%$ of the sample population presented with anorexia, in contrast to the $70-100 \%$ of patients in textbooks and literature who present with anorexia. This is the first study who validate this theory.

\begin{tabular}{|c|c|c|}
\hline \multicolumn{3}{|c|}{ Table 4: Comparison of literature with our study. } \\
\hline Symptoms & Textbook Frequency & Study \% $(95 \%$ Ci) \\
\hline Abdominal Pain & $98-100 \%$ & $98.0(97.3,98.7)$ \\
\hline Anorexia & $70-100 \%$ & $17.6(15.7,19.5)$ \\
\hline Nausea & $67-90 \%$ & $47.2(44.7,49.7)$ \\
\hline Vomiting & $67-75 \%$ & $51.8(49.3,54.3)$ \\
\hline Fever\& Chills & $20 \%$ & $45.0(42.5,47.5)$ \\
\hline Dysuria \& Frequency & $10 \%$ & $13.1(11.4,14.7)$ \\
\hline Constipation & $4 \%$ & $2.7(1.9,3.5)$ \\
\hline
\end{tabular}


Patients presented at the Emergency Department either with no fever or with a low-grade fever. The mean temperature found in the patients in the study was $37.3^{\circ} \mathrm{C}$, compared to the mean temperature reported in emergency medicine textbooks and literature of $37.9^{\circ} \mathrm{C} .22 \%$ of the patients who reported having a recent history of fever, were found afebrile upon evaluation in the ED, and some acknowledged having used acetaminophen before visiting the ED.

Rebound tenderness was found in $75.1 \%$ of the patients, compared to the $68 \%$ reported in textbooks. Cervical motion tenderness was found in $19 \%$ of the patients, compared to the $30 \%$ reported by the textbooks; however, only $30 \%$ of the female patients in our sample population had a documented pelvic examination during their initial evaluations. Rectal tenderness was reported only in $10 \%$ of our studied population, compared to the $40 \%$ reported in academic books and in the literature; but similar to cervical motion tenderness, a limited number of patients had rectal exams performed during their initial evaluation. Psoas sign was found in $39.1 \%$ of the sample patients compared to the $13 \%$ reported by textbooks, and obturator sign was found in $38.0 \%$ compared to the reported $8 \%$ in textbooks and literature.

Laboratory workup mainly found leukocytosis and pyuria in our sample population. Our study revealed that $50.2 \%$ of the patients with appendicitis had leukocytes above $11,000 / \mathrm{uL}$, compared to the documented $75 \%$ of patients in the literature (leukocytosis being $10,000 / \mathrm{uL}$ or higher). Seventeen percent of patients in our study sample presented with pyuria on urinalysis, compared to the $19 \%$ described in the literature.

\section{Conclusion}

It was our main objective to compare the presenting signs and symptoms of patients with acute appendicitis in a specific Hispanic population in the southern region of PR with the presentation found in major textbooks. Our study results showed that the clinical presentation of our study population had no significant difference when compared to the presentation given in textbooks and in the literature. One key difference that was observed was the absence of anorexia in our study population. Psoas and obturator signs were found more frequently in our study than they were in the literature; however, not all patients who were included in the study sample had these maneuvers performed during their physical examinations.

The difference in the incidence of anorexia is of great significance for the future evaluation of Hispanic patients with suspected acute appendicitis. The presence of anorexia should raise the suspicion of appendicitis in a patient with abdominal pain, but its absence should not rule out the possibility of appendicitis, especially in the evaluation of a Hispanic population.

\section{References}

1. Addiss DG, Shaffer N, Fowler BS, Tauxe RV. The epidemiology of appendicitis and appendectomy in the United States. Am J Epidemiol. 1990; 132: 910-925.

PubMed: https://www.ncbi.nlm.nih.gov/pubmed/2239906

2. Calder JD, Gajraj H. Recent advances in the diagnosis and treatment of acute appendicitis. Br J Hosp Med. 1995; 54: 129-133. PubMed: https://www.ncbi.nlm.nih.gov/pubmed/7582361

3. Catto JA. Acute Appendicitis, Tintinalli, Ruiz, Krome, Emergency Medicine, A Comprehensive Study Guide, 4th edition. Mc Graw Hill. 1996; 461-463.

4. Domeier RM. Acute appendicitis. Foresight. 1996; 39: 1-5.

5. Greenfield RH, Henneman PL. Disorders of the Small Intestine, Appendicitis: Rosen, Barkin, Emergency Medicine, Concepts and Clinical Practice. 4th edition. Mosby. 1998; 2005-2011.

6. Jess P, Bjerregaard B, Brynitz S, Holst-Christensen J, Kalaja E, et al. Acute appendicitis. Prospective trial concerning diagnostic accuracy and complications. Am J Surg. 1981; 141: 232-234. PubMed: https://www.ncbi.nlm.nih.gov/pubmed/7457743

7. Liu CD, McFadden DW. Acute abdomen and appendix. In: Greenfield LJ. Et al., eds. Surgery: scientific principles and practice. $2 \mathrm{~d}$ ed. Philadelphia: Lippincott-Raven. 1997; 1246-1261.

8. Norton, Steele, Eiseman. Surgical Decision Making. 3rd edition. Saunders. 1993; 154-155.

9. Orr RK, Porter D, Hartman D. Ultrasonography to evaluate adults for appendicitis: Decision making based on meta-analysis and probabilistic reasoning. Acad Emerg Med. 1995; 2: 644-650. PubMed: https://www.ncbi.nlm.nih.gov/pubmed/8521213

10. Paulman AA, Huebner DM Forrest TS. Sonography in the diagnosis of acute appendicitis. Am Fam Physician. 1991; 44: 465-468. PubMed: https://www.ncbi.nlm.nih.gov/pubmed/1858603

11. Rao PM, Rhea JT, Rao JA, Conn AK. Plain abdominal radiography in clinically suspected appendicitis: diagnostic yield, resource use, and comparison with CT. Am J Emerg Med. 1999; 17: 325-328. PubMed: https://www.ncbi.nlm.nih.gov/pubmed/10452424

12. Ricci Ma, Trevisani MF, BeckWC. Acute appendicitis: a 5-year review. Am Surg. 1991; 57: 301-305.

PubMed: https://www.ncbi.nlm.nih.gov/pubmed/2039128

13. Roake JA, Morton J. Acute appendicitis: a quality assurance analysis. NZ Med J. 1983; 96: 788-790.

PubMed: https://www.ncbi.nlm.nih.gov/pubmed/6578449

14. Rypins EB, Evans DG, Hinrichs W. Tc-99m-HMPAO white blood cell scan for diagnosis of acute appendicitis in patients with equivocal clinical presentation. Ann Surg. 1997; 226: 58-65.

PubMed: https://www.ncbi.nlm.nih.gov/pubmed/9242338

15. Sabiston Jr DC. Appendicitis, Sabiston, Textbook of Surgery. The Biological Basis of Modern Surgical Practice. 1997; 964-970.

16. Schulte B, Beyer D, Kaiser C, Horsch S, Wiater A. Ultrasonography in suspected acute appendicitis in childhood: report of 1285 cases. Eur J Ultrasound. 1998; 8: 177-182.

PubMed: https://www.ncbi.nlm.nih.gov/pubmed/9971899

17. Schwartz SI. Appendix. In: Schwartz SI, ed. Principles of Surgery. 1994; 1307-1318.

18. TempleCL,HuchcroftSA,TempleWJ. Thenatural history ofappendicitis in adults: a prospective study. Ann Surg. 1995; 221: 728-781. PubMed: https://www.ncbi.nlm.nih.gov/pubmed/7717781

19. Wilcox RT, Traverso LW. Have the evaluation and treatment of acute appendicitis changed with new technology. Surg Clin North Am. 1997; 77: 1355-1370.

PubMed: https://www.ncbi.nlm.nih.gov/pubmed/9431344 